\title{
Racial disparities of Black Americans hospitalized for decompensated liver cirrhosis
}

\author{
Ted Spiewak', Amir Taefi ${ }^{2}$, Shruti Patel ${ }^{1}$, Chin-Shang Li ${ }^{3}$ and Eric Chak ${ }^{2^{*}}$ (D)
}

\begin{abstract}
Background: Racial disparities have been reported in liver transplantation and chronic hepatitis $C$ treatment outcomes. Determining causes of these disparities is important given the racially diverse American population and the economic burden associated with chronic liver disease.

Methods: A retrospective study was performed among 463 patients diagnosed with cirrhosis admitted from (January 1, 2013 to January 1, 2018) to a tertiary care academic medical center. Patients were identified based on the International Classification of Diseases (ICD-10) for cirrhosis or its complications. Demographic information, laboratory data, medical comorbidities, insurance and adherence to cirrhosis quality care indicators were recorded to determine their relationship to readmission rates and other healthcare outcomes.

Results: A total of 463 individual patients with cirrhosis were identified including Whites $(n=241)$, Hispanics $(n=$ 106), Blacks ( $n=50)$, Asian and Pacific Islander Americans (API, $n=27)$ and Other $(n=39)$. A significantly higher proportion of Blacks had Medicaid insurance compared to Whites (40\% versus $20 \%, p=0.0002$ ) and Blacks had lower median income than Whites $(\$ 45,710$ versus $\$ 54,844, p=0.01$ ). All groups received high quality cirrhosis care. Regarding healthcare outcomes, Black patients had the highest mean total hospital admissions $(6.1 \pm 6.3, p=0.01)$ and the highest mean number of 30-day re-admissions $(2.1 \pm 3.7, p=0.05)$ compared to all other racial groups. Multivariable proportional odds regression analysis showed that race was a statistically significant predictor of 90day readmission $(p=0.03)$.

Conclusions: Black Americans hospitalized for complications of cirrhosis may experience significant disparities in healthcare outcomes compared to Whites despite high quality cirrhosis care. Socioeconomic factors may contribute to these disparities.
\end{abstract}

Keywords: African Americans, Liver cirrhosis, Health care disparities

\footnotetext{
* Correspondence: echak@ucdavis.edu

${ }^{2}$ Department of Gastroenterology and Hepatology, UC Davis Medical Center,

4150 V Street, PSSB 3500, Sacramento, CA 95817, USA

Full list of author information is available at the end of the article
}

(C) The Author(s). 2020 Open Access This article is licensed under a Creative Commons Attribution 4.0 International License, which permits use, sharing, adaptation, distribution and reproduction in any medium or format, as long as you give appropriate credit to the original author(s) and the source, provide a link to the Creative Commons licence, and indicate if changes were made. The images or other third party material in this article are included in the article's Creative Commons licence, unless indicated otherwise in a credit line to the material. If material is not included in the article's Creative Commons licence and your intended use is not permitted by statutory regulation or exceeds the permitted use, you will need to obtain permission directly from the copyright holder. To view a copy of this licence, visit http://creativecommons.org/licenses/by/4.0/ The Creative Commons Public Domain Dedication waiver (http://creativecommons.org/publicdomain/zero/1.0/) applies to the data made available in this article, unless otherwise stated in a credit line to the data. 


\section{Background}

The care of patients with chronic liver disease and cirrhosis is a costly endeavor for the United States healthcare system. The most recent estimates suggest that at least $\$ 2.5$ billion yearly is spent on the care of these high-risk liver patients alone $[1,2]$. Hospital readmissions among those with decompensated cirrhosis are a common and preventable occurrence with up to $53 \%$ of patients readmitted within 90 days $[3,4]$. Due to the alarming cost of hospital readmissions, [5] interventions to reduce cirrhosis readmission have been developed to address this problem $[6,7]$.

According to the Centers for Disease Control and Prevention $(\mathrm{CDC})$, health disparities are defined as preventable differences in the burden of disease, injury, violence, or opportunities to achieve optimal health that are experienced by socially disadvantaged populations. Racial and ethnic minorities have been shown to experience lower quality of health services compared to White Americans across a spectrum of chronic disease [8]. Racial disparities in liver transplantation $[9,10]$ and chronic hepatitis $C$ treatment response have previously been reported [11].

Racial disparities in cirrhosis is an emerging area of research. It has previously been shown that non-White race has been associated with more frequent re-admission in patients with cirrhosis [12]. Further, an analysis of the Nationwide Inpatient Sample showed that Blacks and Hispanics were less likely to receive portosystemic shunt and liver transplantation compared to Whites and Blacks had higher in-hospital mortality than Whites [13]. More recently, in a large analysis of patients with cirrhosis across 4 American safety-net hospitals, no racial differences in mortality and 30-day were found [14]. Similarly, a nationwide sample showed increased unadjusted odds of mortality among Blacks, which dissipated after adjustment for potential confounders [15]. Thus, the effect of race on cirrhosis health outcomes is not well established.

Decreasing health disparities becomes increasingly important over time since racial and ethnic minorities may comprise over half of the United States population by 2050 [16]. Since death from cirrhosis or end stage liver disease is relatively common in United States [17], reducing cirrhosis-related health disparities will also serve to benefit the wellness of our population as a whole. The purpose of our study is to analyze the effect of race, income, and health insurance on cirrhosis-related outcomes such as receipt of quality cirrhosis care, hospital readmission, and mortality among patients hospitalized for decompensated cirrhosis.

\section{Methods}

\section{Study design and patient population}

We performed a retrospective study of all patients diagnosed with cirrhosis and admitted to UC Davis Medical Center (UCDMC) between January 1, 2013 and January 1, 2018, a tertiary care academic medical center. Any available data prior to January 1, 2013 was not analyzed to emphasize the most current data available. Medical chart review was performed of the UCDMC electronic medical records, with patients identified initially based on the International Classification of Diseases (ICD-10) for cirrhosis or its complications. On October 1, 2015, ICD-10 became available in the United States. At that time, our electronic health record system (Epic Systems, Verona, WI) automatically converted all existing ICD-9 codes to the equivalent ICD-10 codes. Thus, during data abstraction for this study, all codes had been converted to ICD-10 codes. The specific (ICD-10) codes used to determine cirrhosis and complications of cirrhosis included, alcoholic cirrhosis of the liver without ascites (K70.30), alcoholic cirrhosis of the liver with ascites (K70.31), unspecified cirrhosis of the liver (K74.60), other cirrhosis of the liver (K74.69) esophageal varices with bleeding (I85.01), gastric varices (I86.4), hepatic failure, unspecified with coma (K72.91), other ascites (R18.8) or spontaneous bacterial peritonitis (SBP) (K65.2). Demographic information, laboratory data, medical comorbidities, insurance, adherence to cirrhosis quality care indicators, 30 and 90-day readmission, and 30 and 90 day mortality were recorded for analysis. Median income was determined by zip code using a publically available online database (Income By Zip Code) of the American Community Survey 2017 5-year estimates. This study was approved by the Institutional Review Board at UCDMC.

For our study, we focused on the 3 major types of insurance in the United States: Medicare, Medicaid, and private insurance. Both Medicare and Medicaid are federal insurance programs. Medicare covers patients ages 65 and older (or ages less than 65 with a disability and dialysis patients). Medicaid covers low-income patients regardless of age. Lastly, private insurance is purchased by individuals or their employers. Thus, American patients with higher income are more likely to hold private insurance.

\section{Adherence to cirrhosis quality indicators}

We determined adherence to cirrhosis quality indicators by assessing the following: receiving beta-blockers at discharge for secondary prophylaxis after being admitted for variceal bleed, receiving prophylactic antibiotics (IV ceftriaxone or equivalent) in the setting acute variceal hemorrhage, receiving diuretics at discharge for medium to large ascites in the absence of renal failure, receiving spontaneous bacterial peritonitis (SBP) prophylaxis at discharge with after diagnosis and treatment of SBP, receiving intravenous albumin as an inpatient in the setting acute SBP $(1.5 \mathrm{~g} / \mathrm{kg}$ IV on day 1 , then $1 \mathrm{~g} / \mathrm{kg}$ on day 3), receiving IV antibiotics (cefotaxime or equivalent) for treatment of SBP, and receiving lactulose and/or rifaximin for hepatic encephalopathy (HE). Patients who did not receive this level of care in any of these categories were counted as non-adherent for our analyses for each respective category. 


\section{Statistical analysis}

Descriptive data was reported as percentages, means \pm SD and medians (with range and confidence interval when appropriate). For comparative analytics, we used KruskalWallis test for continuous/numerical variables and Fisher's exact test for categorical variables. Multivariable proportional odds regression analysis (hereafter called "multivariable regression analysis" unless otherwise specified) analysis was done to identify independent associations connected to racial disparities in cirrhosis related health care and their effect on readmissions and mortality. To create our multivariate regression models for 30 and 90day readmissions and mortality, we adjusted for the following variables: ethnicity, MELD-Na, medical comorbidities (including diabetes, coronary artery disease, and chronic obstructive pulmonary disease), complications of cirrhosis (including hepatic encephalopathy, gastroesophageal varices, ascites, and hepatocellular carcinoma), receipt of aforementioned quality cirrhosis care, English primary language, insurance status, and median income. A $p$ value $<0.05$ was considered significant.

\section{Results}

A total of 463 individual patients with cirrhosis were identified including Whites $(n=241)$, Hispanics $(n=$ 106), Blacks $(n=50)$, and Asian and Pacific Islander Americans (API, $n=27$ ). The remaining 39 patients were categorized as Other. Mean age was $57.2 \pm 10.8$ years and the majority of the patients were male (58.1\%). A significantly higher proportion of Blacks, Hispanics, and API had Medicaid compared to Whites $(p=0.0002)$. Blacks and Hispanics also had lower median income than Whites ( $\$ 45,710$ versus $\$ 54,844, p=0.01$ ) (Table 1$)$. Further, Blacks and Hispanics had higher mean MELDSodium (MELD-Na) scores compared to Whites (28.7 \pm 9.3 and $29.1 \pm 8.5$ versus $26.4 \pm 9.5, p=0.02$ ) (Table 2 ).
Regarding medical co-morbidities, API (70.4\%) and Blacks (44.0\%) had significantly higher prevalence of diabetes mellitus (DM) compared to Whites $(33.3 \%, p=0.004)$. Blacks also had the highest prevalence of coronary artery disease $(54.0 \%$, $p=0.0004)$ and chronic hepatitis $\mathrm{C}(38.0 \%, p<0.0001)$ compared to other racial groups (Table 3).

Adherence to most cirrhosis quality care indicators ranged from 87 to $100 \%$ (Fig. 1) suggesting high quality inpatient cirrhosis care. The exception was that only $53.2 \%$ received the proper dosing of albumin in the setting of SBP. No racial disparities regarding receipt of quality cirrhosis care were identified.

Regarding healthcare outcomes, Black patients had the highest mean total hospital admissions $(6.1 \pm 6.3, p=0.01)$, highest mean number of 30-day re-admissions (2.1 $\pm 3.7, p=$ $0.05)$. Blacks also trended towards the highest mean number of 90-day readmissions $(3.7 \pm 5.5, P=0.10)$ and highest mean total hospital days $(46.3 \pm 54.5, p=0.07)$ (Table 4$)$.

Because Black patients had statistically higher rates of CAD and the highest rates of COPD compared to other races analyzed, this may have confounded the relationship between Black race and hospital readmission. Therefore, multivariable regression analysis was performed to determine if race was an independent predictor of 30 and 90day hospital readmission (Tables 5 and 6). When compared to Whites, Blacks had higher odds of 30day hospital readmission $\mathrm{OR}=2.13$, 95\% CI $(1.14-$ 3.95). Coronary artery disease (CAD), chronic obstructive pulmonary disease (COPD), hepatic encephalopathy (HE), and presence of ascites were all found to be independently associated with 30-day readmission on multivariable regression analysis. Insurance status was also found to be predictive of 30-day readmission. The odds ratio of 30-day readmission for no insurance versus private insurance was $\mathrm{OR}=0.45$, 95\% CI (0.21-0.99) suggesting that no insurance was protective against 30-day readmission (Table 5).

Table 1 Baseline Demographics of Cirrhosis Patients Admitted to UC Davis Health System, January 2013 to January 2018

\begin{tabular}{|c|c|c|c|c|c|c|}
\hline Characteristics & $\begin{array}{l}\text { Whites } \\
(\boldsymbol{N}=241)\end{array}$ & $\begin{array}{l}\text { Hispanics } \\
(\boldsymbol{N}=106)\end{array}$ & $\begin{array}{l}\text { Blacks } \\
(\boldsymbol{N}=50)\end{array}$ & $\begin{array}{l}\text { API } \\
(\boldsymbol{N}=27)\end{array}$ & $\begin{array}{l}\text { Other } \\
(\boldsymbol{N}=39)\end{array}$ & $\boldsymbol{P}$ value \\
\hline Age (Mean $\pm S D)$ & $58.1 \pm 10.7$ & $55.3 \pm 11.3$ & $57.0 \pm 8.6$ & $61.2 \pm 14.5$ & $54.5 \pm 8.7$ & 0.07 \\
\hline Male (\%) & $142(58.9)$ & $67(63.2)$ & $26(52.0)$ & $12(44.4)$ & $22(56.4)$ & 0.40 \\
\hline English Language Primary (\%) & $231(95.9)$ & $83(78.3)$ & $50(100.0)$ & $13(48.2)$ & $36(92.3)$ & $<0.0001$ \\
\hline Insurance (\%) & & & & & & 0.0002 \\
\hline None & $158(34.13)$ & $93(38.59)$ & $27(25.47)$ & $9(18.00)$ & $8(29.63)$ & \\
\hline VA Insurance & $2(0.43)$ & $1(0.41)$ & $1(0.94)$ & $0(0.00)$ & $0(0.00)$ & \\
\hline Private & $27(11.2)$ & $3(2.8)$ & $3(6.0)$ & $0(0.0)$ & $2(5.1)$ & \\
\hline Medicaid & $48(19.9)$ & $44(41.5)$ & $20(40.0)$ & $11(40.7)$ & $8(20.5)$ & \\
\hline Medicare & $72(29.9)$ & $31(29.3)$ & $18(36.0)$ & $8(29.6)$ & $8(20.5)$ & \\
\hline $\begin{array}{l}\text { Median Income } \\
\text { (minimum, maximum) }\end{array}$ & $\begin{array}{l}\$ 54,488.5 \\
(\$ 0, \$ 134,030)\end{array}$ & $\begin{array}{l}\$ 45,710.0 \\
(\$ 29,747,115,600)\end{array}$ & $\begin{array}{l}\$ 45,710.0 \\
(\$ 29,747, \$ 91,539)\end{array}$ & $\begin{array}{l}\$ 47,405.0 \\
(\$ 29,747, \$ 10,2865)\end{array}$ & $\begin{array}{l}\$ 53,728.0 \\
(\$ 29,747, \$ 102,865)\end{array}$ & 0.01 \\
\hline
\end{tabular}


Table 2 Mean Baseline Laboratory Values of Cirrhosis Patients Admitted to UC Davis Health System, January 2013 to January 2018

\begin{tabular}{lllllll}
\hline Characteristics & $\begin{array}{l}\text { Whites } \\
(\boldsymbol{N}=241)\end{array}$ & $\begin{array}{l}\text { Hispanics } \\
(\boldsymbol{N}=106)\end{array}$ & $\begin{array}{l}\text { Blacks } \\
(\boldsymbol{N}=50)\end{array}$ & $\begin{array}{l}\text { API } \\
(\boldsymbol{N}=27)\end{array}$ & $\begin{array}{l}\text { Other } \\
(\boldsymbol{N}=39)\end{array}$ \\
\hline Platelet \pm SD & $120.0 \pm 75.1$ & $104.1 \pm 70.0$ & $108.6 \pm 60.9$ & $114.1 \pm 95.2$ & $98.0 \pm 51.4$ \\
Albumin \pm SD & $2.8 \pm 0.8$ & $2.6 \pm 0.9$ & $2.6 \pm 0.8$ & $2.6 \pm 0.8$ & $2.6 \pm 0.7$ \\
Sodium \pm SD & $135.7 \pm 5.4$ & $135.9 \pm 4.7$ & $136.0 \pm 5.2$ & $137.7 \pm 4.8$ & $135.7 \pm 5.0$ \\
Creatinine \pm SD & $1.6 \pm 1.3$ & $1.4 \pm 1.9$ & $2.5 \pm 2.4$ & $1.4 \pm 1.0$ & $1.4 \pm 1.1$ & 0.04 \\
Total bilirubin \pm SD & $5.8 \pm 9.3$ & $5.4 \pm 7.7$ & $5.5 \pm 7.7$ & $4.2 \pm 8.1$ & $4.7 \pm 7.8$ & 0.03 \\
INR \pm SD & $1.6 \pm 0.8$ & $1.5 \pm 0.5$ & $1.6 \pm 0.6$ & $1.4 \pm 0.4$ & $1.5 \pm 0.4$ & 0.63 \\
MELD-Na \pm SD & $26.4 \pm 9.5$ & $29.1 \pm 8.5$ & $28.7 \pm 9.3$ & $24.2 \pm 10.0$ & $26.6 \pm 9.3$ \\
\hline
\end{tabular}

API Asian and Pacific Islander, INR International normalized ratio, MELD-Na Model for End Stage Liver Disease-Sodium

As shown in Table 6, race was a statistically significant predictor of 90 -day readmission $(p=0.03)$. The odds ratio of 90 day readmission for Black versus White patients was $\mathrm{OR}=4.69$, $95 \% \mathrm{CI}(1.57,13.95)$. Insurance status was also a statistically significant predictor of 90 -day readmission $(p=0.0001)$. The odds ratio of 90-day readmission for Medicaid insurance versus Medicare insurance was $\mathrm{OR}=4.72,95 \% \mathrm{CI}(2.11-10.6)$.

Severity of cirrhosis was also found to be an important independent predictor of 30-day mortality in our cohort. Multivariable binary logistic regression analysis showed a statistically significant association between MELD-Na and 30-day mortality $(\mathrm{OR}=1.06,95 \% \mathrm{CI}(1.03,1.09)$, $p<0.0001$. We did not, however, find a statistically significant association between MELD-Na and 90-day mortality OR $=1.02,95 \% \mathrm{CI}(0.972,1.077), p=0.07$.

\section{Discussion}

In this retrospective cohort study, Black patients admitted for decompensated liver cirrhosis had the highest mean total hospital admissions and mean number of 30day readmissions compared to other racial groups. Black patients also trended towards the highest mean number of hospital days and 90-day readmissions, but these did not reach statistical significance. The disparities that were found may be the result of differences in socioeconomic factors such as insurance status. We found that Black patients were more likely to have Medicaid insurance compared to other racial groups at baseline. On multivariable regression analysis, Black race conferred a 2-fold increased odds in 30-day readmission and a 4-fold increased odds in 90-day readmission compared to

Table 3 Baseline Co-morbidities and Liver Decompensations of Cirrhosis Patients Admitted to UC Davis Health System, January 2013 to January 2018

\begin{tabular}{|c|c|c|c|c|c|c|}
\hline Characteristics & $\begin{array}{l}\text { Whites } \\
(\boldsymbol{N}=241)\end{array}$ & $\begin{array}{l}\text { Hispanics } \\
(\boldsymbol{N}=106)\end{array}$ & $\begin{array}{l}\text { Blacks } \\
(\boldsymbol{N}=50)\end{array}$ & $\begin{array}{l}\mathrm{API} \\
(\boldsymbol{N}=27)\end{array}$ & $\begin{array}{l}\text { Other } \\
(\boldsymbol{N}=39)\end{array}$ & $\boldsymbol{P}$ value \\
\hline Diabetes N (\%) & $80(33.3)$ & $40(37.7)$ & $22(44.0)$ & $19(70.4)$ & $17(44.7)$ & 0.004 \\
\hline Coronary artery disease (\%) & $65(27.0)$ & $25(23.6)$ & $27(54.0)$ & $6(22.2)$ & $5(13.5)$ & 0.0004 \\
\hline COPD (\%) & $50(20.9)$ & $14(13.2)$ & $13(26.0)$ & $4(15.4)$ & $4(10.5)$ & 0.17 \\
\hline Smoking (\%) & $165(69.0)$ & $67(64.4)$ & $37(74.0)$ & $15(55.6)$ & $29(76.3)$ & 0.34 \\
\hline Hepatic encephalopathy (\%) & $151(62.9)$ & $70(66.0)$ & $33(66.0)$ & $17(63.0)$ & $31(79.5)$ & 0.38 \\
\hline Gastro-esophageal varices (\%) & $96(42.3)$ & $61(61.6)$ & $20(41.7)$ & $14(53.9)$ & $19(50.0)$ & 0.02 \\
\hline Ascites (\%) & $163(67.9)$ & $65(61.3)$ & $30(61.2)$ & $17(63.0)$ & $25(64.1)$ & 0.74 \\
\hline Liver cancer (\%) & $2(0.8)$ & $1(1.0)$ & $1(2.0)$ & $2(7.4)$ & $1(2.6)$ & 0.09 \\
\hline Etiology of Liver Disease & & & & & & $<0.0001$ \\
\hline $\mathrm{HCV}(\%)$ & $60(25.0)$ & $26(24.5)$ & $19(38.0)$ & $6(22.2)$ & $9(23.1)$ & \\
\hline Alcohol (\%) & $82(34.2)$ & $46(43.4)$ & $15(30.0)$ & $3(11.1)$ & $15(38.5)$ & \\
\hline HCV + Alcohol (\%) & $36(15.0)$ & $15(14.2)$ & $5(10.0)$ & $0(0.0)$ & $7(18.0)$ & \\
\hline NASH (\%) & $24(10.0)$ & $2(1.9)$ & $0(0.0)$ & $5(18.5)$ & $4(10.3)$ & \\
\hline HBV (\%) & $3(1.3)$ & $0(0.0)$ & $1(2.0)$ & $7(25.9)$ & $0(0.0)$ & \\
\hline Autoimmune, PBC, PSC (\%) & $7(2.9)$ & $4(3.8)$ & $1(2.0)$ & $0(0.0)$ & $0(0.0)$ & \\
\hline Unknown, other (\%) & $28(11.7)$ & $13(12.3)$ & $9(18.0)$ & $6(22.2)$ & $4(10.3)$ & \\
\hline
\end{tabular}




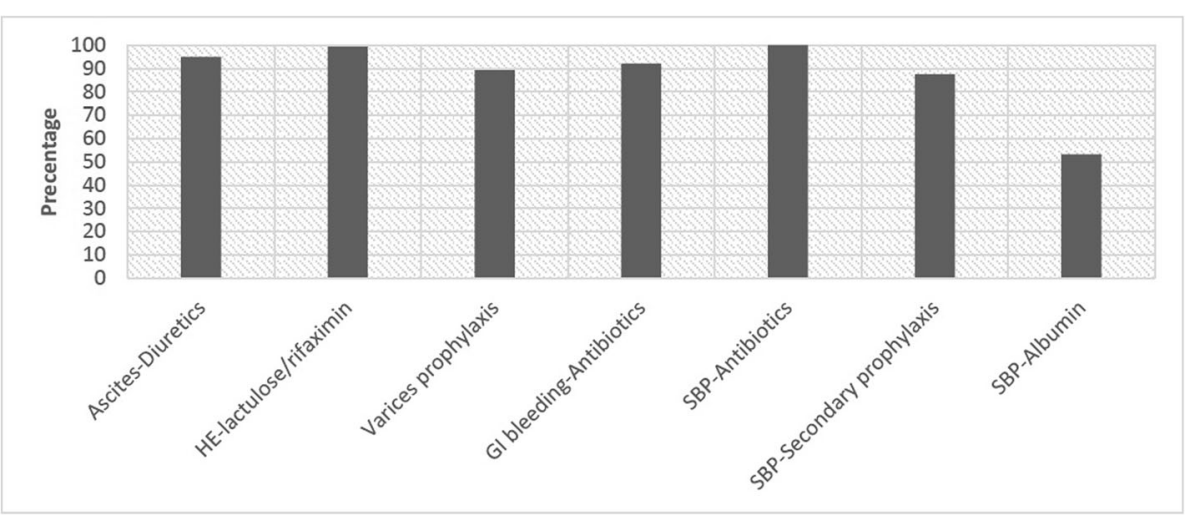

HE: hepatic encephalopathy; GI: gastrointestinal; SBP: spontaneous bacterial peritonitis

Fig. 1 Baseline Adherence to Cirrhosis Quality Indicators at UC Davis Medical Center, January 2013-January 2018

White race. Further, multivariable regression analysis also showed that Medicaid insurance was found to confer a 4-fold increased odds of 90-day readmission compared to Medicare insurance. Interestingly, lack of insurance was associated with lower odds of readmission when compared to private and Medicaid insurance. One explanation for this could be that patients with no insurance also had other socioeconomic disparities (such as lack of transportation to the hospital) that prevented them from being readmitted.

Racial disparities in liver disease may result from a combination of biological, socioeconomic, and cultural factors [18]. After introduction of the MELD score, racial disparities have appeared to decrease regarding receipt of cadaveric liver transplantation [19]. However recent studies have noted that Blacks were less likely than Whites to receive living donor liver transplantation [10] and experience higher rates of liver transplant graft failure compared to Whites [9]. With regard to cirrhosis care, non-White race was independently shown to be associated with a 2-fold increase odds of readmission [12]. In a recent study of patients with hepatocellular carcinoma, Blacks were found to have had a significantly higher mortality compared to Whites after adjusting for tumor stage, liver function, receipt of HCC treatment, and insurance status [20]. Our findings add to the growing body of literature showing that Blacks may experience chronic liver disease disparity.

Differences seen in the receipt and quality of healthcare pertaining to those with liver disease may also be related to health insurance status and lower socioeconomic status. Significant disparities in access to treatment of chronic HCV infection since the approval of direct acting antiviral (DAA) agents, have been reported [21]. Medicaid has been associated with a higher proportion of patients receiving absolute denials [22] and significantly lower odds of treatment [23] than those covered by Medicare and those who are commercially insured. Younossi ZM, et al., reported insurance-specific disparities after analyzing the non-start rates of patients who were prescribed sofosbuvir-based regimens. Nonstart rates were the highest in Medicaid-covered patients at (35\%), as compared to Medicare (2\%) and commercial insurances (6\%). This study also showed that those with commercial coverage were 6.5 times as likely to start sofosbuvir based therapy compared to patients with Medicaid [24]. Medicaid has also been reported to be associated with higher Model for End-Stage Liver Disease

Table 4 Healthcare-Related Outcomes of Cirrhosis Patients Admitted to UC Davis Health System, January 2013 to January 2018

\begin{tabular}{|c|c|c|c|c|c|c|}
\hline Characteristics & $\begin{array}{l}\text { Whites } \\
(\boldsymbol{N}=241)\end{array}$ & $\begin{array}{l}\text { Hispanics } \\
(\boldsymbol{N}=106)\end{array}$ & $\begin{array}{l}\text { Blacks } \\
(\boldsymbol{N}=50)\end{array}$ & $\begin{array}{l}\text { API } \\
(\boldsymbol{N}=27)\end{array}$ & $\begin{array}{l}\text { Other } \\
(\boldsymbol{N}=39)\end{array}$ & $\boldsymbol{P}$ value \\
\hline Mean Total Hospital Admissions & $3.0 \pm 3.0$ & $3.4 \pm 3.8$ & $6.1 \pm 6.3$ & $4.5 \pm 4.7$ & $2.4 \pm 1.8$ & 0.01 \\
\hline Mean Total Hospital Days & $22.0 \pm 23.2$ & $22.2 \pm 23.6$ & $46.3 \pm 54.5$ & $22.8 \pm 21.7$ & $18.0 \pm 20.0$ & 0.07 \\
\hline Mean Length of Hospital Stay (Days) & $7.6 \pm 6.4$ & $7.3 \pm 5.7$ & $7.7 \pm 6.2$ & $5.3 \pm 3.1$ & $7.9 \pm 7.4$ & 0.56 \\
\hline Mean 30-day Readmission & $0.7 \pm 1.5$ & $1.0 \pm 2.2$ & $2.1 \pm 3.7$ & $1.0 \pm 1.5$ & $0.5 \pm 0.7$ & 0.05 \\
\hline Mean 90-day Readmission & $1.4 \pm 2.4$ & $1.5 \pm 3.4$ & $3.7 \pm 5.5$ & $1.9 \pm 2.9$ & $0.9 \pm 1.2$ & 0.10 \\
\hline 30-day mortality (\%) & $60(24.9)$ & $23(21.7)$ & $12(24.0)$ & $4(14.8)$ & $9(23.1)$ & 0.85 \\
\hline 90-day mortality (\%) & $7(2.9)$ & $6(5.7)$ & $3(6.0)$ & $0(0.0)$ & $2(5.1)$ & 0.44 \\
\hline Liver Transplanted (\%) & $9(3.7)$ & $6(5.7)$ & $3(6.0)$ & $0(0.0)$ & $3(7.7)$ & 0.52 \\
\hline
\end{tabular}


Table 5 Multivariable Proportional Odds Regression Analysis of Factors Associated with 30-Day Readmissions at UC Davis Health System, January 2013 to January 2018

\begin{tabular}{llll}
\hline Characteristic & Odds ratio & $95 \% \mathrm{Cl}$ & $\boldsymbol{P}$-value \\
\hline Race & & & 0.21 \\
$\quad$ Black versus White & 2.13 & $1.14-3.95$ & 0.02 \\
$\quad$ Black versus API & 1.94 & $0.72-5.24$ & 0.19 \\
$\begin{array}{l}\text { Co-morbidities } \\
\text { Coronary artery disease }\end{array}$ & 1.76 & $1.10-2.80$ & 0.02 \\
COPD & 1.87 & $1.15-3.05$ & 0.01 \\
Hepatic encephalopathy & 2.42 & $1.53-3.85$ & 0.00002 \\
$\quad$ Diabetes & 1.39 & $0.90-2.15$ & 0.13 \\
Ascites & 1.96 & $1.23-3.11$ & 0.004 \\
Insurance Status & & & 0.005 \\
$\quad$ None versus Private & 0.45 & $0.21-0.99$ & 0.046 \\
None versus Medicaid & 0.40 & $0.23-0.67$ & 0.0006 \\
$\quad$ Medicaid versus Private & 1.15 & $0.53-2.47$ & 0.72 \\
Medicaid versus Medicare & 1.35 & $0.82-2.24$ & 0.24 \\
\hline
\end{tabular}

API Asian and Pacific Islander, COPD chronic obstructive pulmonary disease, $\mathrm{CI}$ confidence interval, NS not significant

(MELD) scores at transplant registration and also associated with worse post-transplant outcomes [25].

Adherence to evidence based cirrhosis care has been previously been described as suboptimal $[26,27]$. In a study of Veterans Affairs patients with cirrhosis complicated by ascites, only $33.2 \%$ of patients receiving all recommended care [28]. Similar findings of suboptimal

Table 6 Multivariable Proportional Odds Regression Analysis of Factors Associated with 90-Day Readmissions at UC Davis Health System, January 2013 to January 2018

\begin{tabular}{llll}
\hline Characteristic & Odds Ratio & $95 \% \mathrm{Cl}$ & $\boldsymbol{P}$-value \\
\hline Race & & & 0.03 \\
$\quad$ Black versus White & 4.69 & $1.57-13.95$ & 0.006 \\
$\quad$ Black versus API & 8.45 & $1.90-37.60$ & 0.005 \\
$\begin{array}{l}\text { Co-morbidities } \\
\text { Coronary artery disease }\end{array}$ & 1.25 & $0.54-2.87$ & 0.60 \\
COPD & 1.54 & $0.67-3.56$ & 0.31 \\
Hepatic encephalopathy & 4.74 & $1.93-11.63$ & 0.0007 \\
$\quad$ Diabetes & 2.07 & $1.01-4.22$ & 0.047 \\
$\quad$ Ascites & 3.91 & $1.61-9.52$ & 0.003 \\
Insurance Status & & & 0.0001 \\
$\quad$ None versus Private & 0.40 & $0.11-1.42$ & 0.35 \\
None versus Medicaid & 0.15 & $0.06-0.39$ & $<0.0001$ \\
$\quad$ Medicaid versus Private & 2.57 & $0.78-8.52$ & 0.12 \\
Medicaid versus Medicare & 4.72 & $2.11-10.6$ & 0.0002 \\
\hline
\end{tabular}

API Asian and Pacific Islander, COPD chronic obstructive pulmonary disease, $\mathrm{Cl}$ confidence interval, NS not significant cirrhosis care have been reported in the setting of variceal bleeding, screening for varices, and HCC surveillance with ultrasound [29-31]. Compared to these previous studies, adherence to evidence based cirrhosis care at our institution was improved with $87-100 \%$ adherence to most quality indicators which may reflect increased awareness of cirrhosis care in the current era. No racial disparities in receipt of quality cirrhosis care were identified in our study, which suggests that racial disparities in cirrhosis outcomes occurred despite high quality cirrhosis care.

Chronic comorbid conditions [32] and complications of liver cirrhosis [33] are both predictors of hospital readmission and poor healthcare outcomes. In patients with cirrhosis, hepatic encephalopathy (HE) and ascites are most strongly associated with readmission within 30 or 90 days [33-35]. Our study's findings align with what is reported in the literature with respect to these well-established risk factors of readmission following a hospitalization for decompensated liver cirrhosis. On multivariable analysis, the presence of HE conferred a 2-fold increased odds in 30day readmission and a 4-fold increased odds in 90-day readmission. The presence of ascites also nearly conferred a 2-fold increased odds in 30-day readmission and a 4-fold increased odds in 90-day readmission. MELD-Na was associated with an increased odds of 30-day mortality on multivariate binary logistic regression analysis. Further, CAD and DM conferred nearly a 2-fold increased odds in 30-day and 90-day readmission, respectively.

Limitations of our study are typical for retrospective design. The categorization of patients as being diagnosed with cirrhosis and its complications by ICD-10 codes and their assignment into racial groups was dependent on accuracy of this information as recorded in the electronic health record. Further, hospital readmission, mortality, and liver transplantation, which occurred outside of our health system, would not have been captured when data was abstracted. Lastly, patients were identified only by ICD-10 code. Thus, we were able to determine the presence of cirrhosis complications such as ascites and hepatic encephalopathy, but we were unable to determine Child-Pugh scores since severity of ascites and hepatic encephalopathy was not captured. Therefore, potential associations between healthcare outcomes and Child-Pugh scores would have been missed.

\section{Conclusions}

We found racial disparities in Black Americans hospitalized for decompensated liver cirrhosis. Black race was independently associated with increased odds of hospital readmission. At baseline, Medicaid insurance was more prevalent in Black patients and was independently associated with higher odds of readmission. This study highlights the need for further etiologic studies on racial disparities in cirrhosis care specifically to identify actionable intervention targets in order to reduce these disparities seen in the Black community. 


\section{Supplementary information}

Supplementary information accompanies this paper at https://doi.org/10. 1186/s12876-020-01392-y.

\section{Additional file 1.}

\section{Abbreviations}

API: Asian and Pacific Islander; CAD: Coronary artery disease; Cl: Confidence interval; COPD: Chronic obstructive pulmonary disease; DM: Diabetes mellitus; DAA: Direct acting antiviral; Gl: Gastrointestinal; HE: Hepatic encephalopathy; ICD: International Classification of Diseases; MELD: Model for end-stage liver disease; SBP: Spontaneous bacterial peritonitis; UCDMC: UC Davis Medical Center

\section{Acknowledgements}

None.

\section{Authors' contributions}

TS (acquisition of data; analysis and interpretation of data; drafting of the manuscript), AT (acquisition of data), SP (acquisition of data), CSL (analysis and interpretation of data; critical revision of the manuscript for important intellectual content; statistical analysis), EC (study concept and design; analysis and interpretation of data; drafting of the manuscript; critical revision of the manuscript for important intellectual content; study supervision). All authors have read and approved the manuscript.

\section{Funding}

Not applicable.

\section{Availability of data and materials}

All data generated or analyzed during this study are included in this published article as a supplemental file.

\section{Ethics approval and consent to participate}

This study was approved by the Institutional Review Board of UC Davis Medical Center.

\section{Consent for publication}

Not applicable.

\section{Competing interests}

The other authors have no potential competing interests to be disclosed, including (financial, professional, or personal) that were relevant to this manuscript.

\section{Author details}

'Department of Internal Medicine, UC Davis Medical Center, Sacramento, California, USA. ²Department of Gastroenterology and Hepatology, UC Davis Medical Center, 4150 V Street, PSSB 3500, Sacramento, CA 95817, USA. ${ }^{3}$ School of Nursing, The State University of New York at Buffalo, Buffalo, New York, USA.

Received: 23 June 2019 Accepted: 21 July 2020

Published online: 29 July 2020

\section{References}

1. Kim WR, Brown RS Jr, Terrault NA, El-Serag H. Burden of liver disease in the United States: summary of a workshop. Hepatology. 2002;36(1):227-42.

2. Neff GW, Duncan CW, Schiff ER. The current economic burden of cirrhosis. Gastroenterol Hepatol (N Y). 2011;7(10):661-71.

3. Volk ML, Tocco RS, Bazick J, Rakoski MO, Lok AS. Hospital readmissions among patients with decompensated cirrhosis. Am J Gastroenterol. 2012; 107(2):247-52

4. Bajaj JS, Reddy KR, Tandon P, Wong F, Kamath PS, Garcia-Tsao G, Maliakkal B, Biggins SW, Thuluvath PJ, Fallon MB, Subramanian RM Vargas H, Thacker LR, O'Leary JG. North American consortium for the study of end-stage liver disease: the 3-month readmission rate remain unacceptably high in a large north American cohort of patients with cirrhosis. Hepatology. 2016;64(1):200-8
5. Jencks SF, Williams MV, Coleman EA. Rehospitalizations among patients in the Medicare fee-for-service program. N Engl J Med. 2009;360(14):1418-28.

6. Tapper EB, Finkelstein D, Mittleman MA, Piatkowski G, Chang M, Lai M. A quality improvement initiative reduces 30-day rate of readmission for patients with cirrhosis. Clin Gastroenterol Hepatol. 2016;14(5):753-9.

7. Morando F, Maresio G, Piano S, Fasolato S, Cavallin M, Romano A, Rosi S, Gola E, Frigo AC, Stanco M, Destro C, Rupolo G, Mantoan D, Gatta A, Angeli $P$. How to improve care in outpatients with cirrhosis and ascites: a new model of care coordination by consultant hepatologists. J Hepatol. 2013; 59(2):257-64.

8. Institute of Medicine (US) Committee on understanding and eliminating racial and ethnic disparities in health care: 2003 ,

9. Mathur AK, Schaubel DE, Zhang H, Guidinger MK, Merion RM. Disparities in liver transplantation: the association between donor quality and recipient race/ethnicity and sex. Transplantation. 2014;97(8):862-9.

10. Nobel YR, Forde KA, Wood L, Cartiera K, Munoz-Abraham AS, Yoo PS, Abt PL, Goldberg DS. Racial and ethnic disparities in access to and utilization of living donor liver transplants. Liver Transpl. 2015;21(7):904-13.

11. Brau N, Bini EJ, Currie S, Shen H, Schmidt WN, King PD, Ho SB, Cheung RC, Hu KQ, Anand BS, Simon FR, Aytaman A, Johnson DP, Awad JA, Ahmad J, Mendenhall CL, Pedrosa MC, Moseley RH, Hagedorn CH, Waters B, Chang KM, Morgan TR, Rossi SJ, Jeffers LJ, Wright TL, VA-HCV-001 Study Group. Black patients with chronic hepatitis $C$ have a lower sustained viral response rate than non-Blacks with genotype 1, but the same with genotypes 2/3, and this is not explained by more frequent dose reductions of interferon and ribavirin*. J Viral Hepat. 2006:13(4):242-9.

12. Ganesh S, Rogal SS, Yadav D, Humar A, Behari J. Risk factors for frequent readmissions and barriers to transplantation in patients with cirrhosis. PLoS One. 2013;8(1):e55140

13. Nguyen GC, Segev DL, Thuluvath PJ. Racial disparities in the management of hospitalized patients with cirrhosis and complications of portal hypertension: a national study. Hepatology. 2007:45(5):1282-9.

14. Mukthinuthalapati WPK, Akinyeye S, Fricker ZP, Syed M, Orman ES, Nephew L, Vilar-Gomez E, Slaven J, Chalasani N, Balakrishnan M, Long MT, Attar BM, Ghabril M. Early predictors of outcomes of hospitalization for cirrhosis and assessment of the impact of race and ethnicity at safety-net hospitals. PLoS One. 2019;14(3):e0211811.

15. Chakrabarti A, Osborne NH, Rangnekar AS, Mathur AK. The effect of hospital characteristics on racial/ethnic variation in cirrhosis mortality. J Racial Ethn Health Disparities. 2017:4(2):243-51.

16. De Vita CJ, Pollard KM. Increasing diversity of the U.S. population. Stat Bull Metrop Insur Co. 1996;77(3):12-7.

17. Tapper EB, Parikh ND. Mortality due to cirrhosis and liver cancer in the United States, 1999-2016: observational study. BMJ. 2018;362:k2817.

18. Nguyen GC, Thuluvath PJ. Racial disparity in liver disease: biological, cultural or socioeconomic factors. Hepatology. 2008;47(3):1058-66.

19. Moylan CA, Brady CW, Johnson JL, Smith AD, Tuttle-Newhall JE, Muir AJ. Disparities in liver transplantation before and after introduction of the MELD score. JAMA. 2008;300(20):2371-8.

20. Rich NE, Hester C, Odewole M, Murphy CC, Parikh ND, Marrero JA, Yopp AC, Singal AG. Racial and ethnic differences in presentation and outcomes of hepatocellular carcinoma. Clin Gastroenterol Hepatol. 2019;17(3):551-9 e1.

21. Zuckerman A, Carver A, Chastain CA. Building a hepatitis C clinical program: strategies to optimize outcomes. Curr Treat Options Infect Dis. 2018;10(4):431-46.

22. Lo Re V 3rd, Gowda C, Urick PN, Halladay JT, Binkley A, Carbonari DM, Battista K, Peleckis C, Gilmore J, Roy JA, Doshi JA, Reese PP, Reddy KR, Kostman JR. Disparities in absolute denial of modern hepatitis $C$ therapy by type of insurance. Clin Gastroenterol Hepatol. 2016;14(7):1035-43.

23. Wong RJ, Jain MK, Therapondos G, Shiffman ML, Kshirsagar O, Clark C, Thamer M Race/ethnicity and insurance status disparities in access to direct acting antivirals for hepatitis C virus treatment. Am J Gastroenterol. 2018;113(9):1329-38.

24. Younossi ZM, Bacon BR, Dieterich DT, Flamm SL, Kowdley K, Milligan S, Tsai $\mathrm{N}$, Nezam A. Disparate access to treatment regimens in chronic hepatitis $C$ patients: data from the TRIO network. J Viral Hepat. 2016;23(6):447-54.

25. Kemmer N, Zacharias V, Kaiser TE, Neff GW. Access to liver transplantation in the MELD era: role of ethnicity and insurance. Dig Dis Sci. 2009:54(8):1794-7.

26. Tey KR, Mohan P, Liu X, Desai AP. Closing the quality chasm in cirrhosis. Clin Liver Dis (Hoboken). 2018:12(2):45-9.

27. Sclair SN, Carrasquillo O, Czul F, Trivella JP, Li H, Jeffers L, Martin P. Quality of care provided by Hepatologists to patients with cirrhosis at three parallel health systems. Dig Dis Sci. 2016;61(10):2857-67. 
28. Kanwal F, Kramer JR, Buchanan P, Asch SM, Assioun Y, Bacon BR, Li J, ElSerag HB. The quality of care provided to patients with cirrhosis and ascites in the Department of Veterans Affairs. Gastroenterology. 2012;143(1):70-7.

29. Buchanan PM, Kramer JR, El-Serag HB, Asch SM, Assioun Y, Bacon BR, Kanwal F. The quality of care provided to patients with varices in the department of Veterans Affairs. Am J Gastroenterol. 2014;109(7):934-40.

30. Flemming JA, Saxena V, Shen H, Terrault NA, Rongey C. Facility- and patient-level factors associated with esophageal Variceal screening in the USA. Dig Dis Sci. 2016;61(1):62-9.

31. Davila JA, Henderson L, Kramer JR, Kanwal F, Richardson PA, Duan Z, ElSerag HB. Utilization of surveillance for hepatocellular carcinoma among hepatitis C virus-infected veterans in the United States. Ann Intern Med. 2011;154(2):85-93.

32. Donze J, Lipsitz S, Bates DW, Schnipper JL. Causes and patterns of readmissions in patients with common comorbidities: retrospective cohort study. BMJ. 2013;347:f7171.

33. Orman ES, Ghabril M, Emmett TW, Chalasani N. Hospital readmissions in patients with cirrhosis: a systematic review. J Hosp Med. 2018;13(7):490-5.

34. Tapper EB, Halbert B, Mellinger J. Rates of and reasons for hospital readmissions in patients with cirrhosis: a multistate population-based cohort study. Clin Gastroenterol Hepatol. 2016;14(8):1181-8 e2.

35. Shaheen AA, Nguyen HH, Congly SE, Kaplan GG, Swain MG. Nationwide estimates and risk factors of hospital readmission in patients with cirrhosis in the United States. Liver Int. 2019;39(5):878-84.

\section{Publisher's Note}

Springer Nature remains neutral with regard to jurisdictional claims in published maps and institutional affiliations.

Ready to submit your research? Choose BMC and benefit from:

- fast, convenient online submission

- thorough peer review by experienced researchers in your field

- rapid publication on acceptance

- support for research data, including large and complex data types

- gold Open Access which fosters wider collaboration and increased citations

- maximum visibility for your research: over $100 \mathrm{M}$ website views per year

At BMC, research is always in progress.

Learn more biomedcentral.com/submissions 